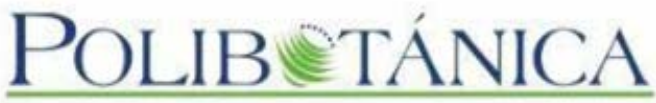

Polibotánica

ISSN electrónico: 2395-9525

polibotanica@gmail.com

Instituto Politécnico Nacional

México

http://www.polibotanica.mx

\title{
COMPARACIÓN MOLECULAR Y MORFOLÓGICA ENTRE EJEMPLARES DE Magnolia mexicana "YOLOXÓCHITL" (MAGNOLIACEAE) DEL ESTADO DE MÉXICO Y VERACRUZ.
}

\section{MOLECULAR AND MORPHOLOGICAL} COMPARISON BETWEEN Magnolia mexicana "YOLOXOCHITL" SPECIMENS (MAGNOLIACEAE) FROM THE STATE OF MEXICO AND VERACRUZ.

Arteaga-Rios, L. D., J. Mejía-Carraza, J. L. Piña-Escutia, J. G. González-Díaz y A. Rivera-Colín. COMPARACIÓN MOLECULAR Y MORFOLÓGICA ENTRE EJEMPLARES DE Magnolia mexicana "YOLOXÓCHITL" (MAGNOLIACEAE) DEL ESTADO DE MÉXICO Y VERACRUZ. MOLECULAR AND MORPHOLOGICAL COMPARISON BETWEEN Magnolia mexicana "YOLOXOCHITL" SPECIMENS (MAGNOLIACEAE) FROM THE STATE OF MEXICO AND VERACRUZ.

POLIBETÁNICA Instituto Politécnico Nacional
Núm. 49: 107-124 México. Enero 2020

DOI: $10.18387 /$ polibotanica.49.7

(c) (†) Este es un artículo de acceso abierto bajo la licencia Creative Commons 4.0 Atribución-No Comercial (CC BY-NC 4.0 Internacional). 


\title{
COMPARACIÓN MOLECULAR Y MORFOLÓGICA ENTRE EJEMPLARES DE Magnolia mexicana "YOLOXÓCHITL" (MAGNOLIACEAE) DEL ESTADO DE MÉXICO Y VERACRUZ
}

\author{
MOLECULAR AND MORPHOLOGICAL COMPARISON BETWEEN \\ Magnolia mexicana "YOLOXOCHITL" SPECIMENS (MAGNOLIACEAE) \\ FROM THE STATE OF MEXICO AND VERACRUZ
}

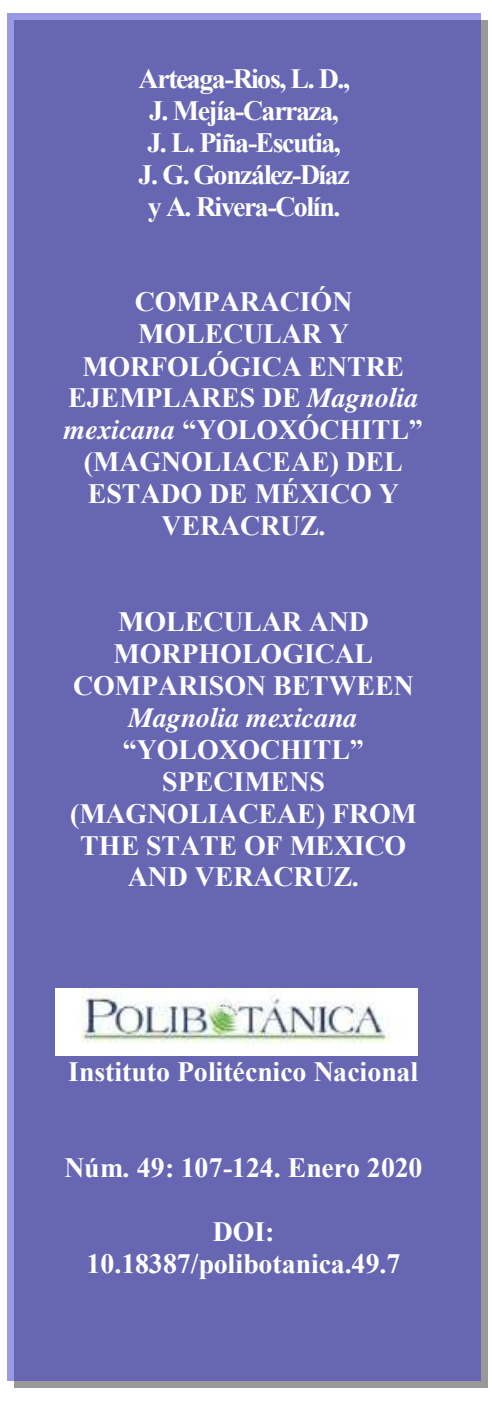

RESUMEN: El término "Yoloxóchitl" se ha asociado históricamente con Magnolia mexicana (Magnoliaceae), especie amenazada por la disminución en sus poblaciones y áreas donde prospera. La presencia de dos árboles únicos posiblemente de esta especie en Malinalco y Zumpahuacán, Estado de México, genera interrogantes sobre su historia y alcances de su distribución. El objetivo del presente estudio fue establecer las relaciones moleculares y morfológicas existentes entre dichos individuos, con otros de M. mexicana presentes en Zongolica, Veracruz. Se colectaron muestras de tejido vegetal, y se determinaron 18 caracteres morfológicos de árboles provenientes de los municipios del Estado de México, así como de M. mexicana, provenientes de Acontla y La Quinta en Zongolica, Veracruz. Así mismo, como referentes de contraste molecular, se utilizaron muestras de $M$. dealbata y $M$. grandiflora. Se analizaron 14 iniciadores RAPD que amplificaron 205 bandas, obteniendo valores promedio PIC de 0.30 y RP de 5.42, respectivamente. Los iniciadores OPA7, OPA8 y E18 mostraron la mayor capacidad discriminante. El análisis de agrupamiento formó tres conjuntos, dos de ellos para los referentes $M$. grandiflora y $M$. dealbata, y el tercero, agrupó a $M$. mexicana con los individuos de Malinalco y Zumpahuacán, compartiendo una similitud genética del 87 y 90\% respectivamente. Se observó además variación morfológica en 14 de 18 caracteres entre los individuos provenientes de Veracruz y los del Estado de México. Los resultados indicaron que los árboles de Yoloxóchitl de Malinalco y Zumpahuacán pertenecen a la sección Talauma, sin embargo, muestran amplia variación morfológica respecto a M. mexicana.

Palabras clave: Sección Talauma, Magnolia mexicana, RAPD. 


\begin{abstract}
The term "Yoloxochitl" has historically been associated with Magnolia Mexicana (Magnoliaceae), a threatened species due to the decrease in its populations and areas where it thrives. The presence of two trees possibly of this species in Malinalco and Zumpahuacan, State of Mexico, raises questions about its history and scope of its distribution. The objective of the present study was to establish the existing molecular and morphological relationships between these individuals, with others of $M$. mexicana present in Zongolica, Veracruz. Samples of plant tissue were collected, and 18 morphological characters of trees from the municipalities of the State of Mexico, as well as M. mexicana, from Acontla and La Quinta in Zongolica Vercruz were determined. Also, as references of molecular contrast, samples of $M$. dealbata and M. grandiflora were used. 14 RAPD primers were analyzed, that amplified 205 bands, obtaining average PIC values of 0.30 and RP of 5.42, respectively. The cluster analysis formed three sets, two of them for the referents $M$. grandiflora and $M$. dealbata, and the third, grouped M. mexicana with the individuals of Malinalco and Zumpahuacan, sharing a genetic similarity of 87 and $90 \%$ respectively. Morphological variation was also observed in 14 of 18 characters between individuals from Veracruz and those of the State of Mexico. The results indicated that the Yoloxochitl trees of Malinalco and Zumpahuacan belong to the Talauma section, however, they show a wide morphological variation with respect to M. mexicana.
\end{abstract}

Key words: Talauma section, Magnolia mexicana, RAPD.

\title{
INTRODUCCIÓN
}

El estudio de las magnolias (Magnoliaceae) de México en los últimos 25 años ha conducido a la descripción de nuevas especies, al pasar de once en 1994 (Lozano-Contreras, 1994; VázquezGarcía, 1994) a más de 40 en la actualidad (Gómez-Domínguez, Pérez-Farrera, VázquezGarcía, Sahagún-Godínez, \& Muñiz-Castro, 2017; Vázquez-García et al., 2014); la mayoría de ellas endémicas y con limitaciones en información sobre su distribución, biología y ecología, que enfrentan serias amenazas a su permanencia (Rivers, Beech, Murphy, \& Oldfield, 2016).

En particular, Magnolia mexicana (DC.) (Sección Talauma, Subsección Talauma), que se consideró la única especie de la sección Talauma en México (Lozano-Contreras, 1994), ha sido clave en el nuevo inventario de las magnolias del país, al reclasificarse algunas de sus poblaciones a Magnolia zoquepopolucae (Vázquez-García, De Castro-Arce, Muñiz-Castro, \& Cházaro-Basañez, 2012), M. lopezobradori, M. sinacacolinii, M. jaliscana (Vázquez-García, Muñiz-Castro, et al., 2012), M. perezfarrerae (Vázquez-García, Gómez-Domínguez, et al., 2013), M. lacandonica (Vázquez-García, Pérez-Farrera, Martínez-Camilo, Muñiz-Castro, \& Martínez-Meléndez, 2013), M. macrocarpa, M. wendtii, M. ofeliae y M. decastroi (VázquezGarcía, Muñiz-Castro, et al., 2013); y por lo tanto, ha replanteado su área de distribución a poblaciones relictuales en los estados de Oaxaca, Puebla y Veracruz, (Rivers, Martínez Salas, \& Samain, 2016).

Históricamente M. mexicana, y ahora sus reclasificaciones, se ha asociado al nombre náhuatl "Yoloxóchitl" (de Candolle, 1818; Lozoya, 1999; Waizel-Bucay, 2002; Micheli, 2004), y se señaló a los estados de Veracruz, Morelos y Ciudad de México como sitios de origen y distribución (de Candolle, 1818; Sessé \& Mociño, 1894), que tenía concordancia con lo asentado en el Códice Durán donde se relata que durante el reinado de Moctezuma I, fueron traídos éstos árboles desde la provincia de Cuetlaxtla (actual Veracruz), a lo que hoy es Oaxtepec en el Estado de Morelos para conformar el que fue el primer jardín botánico de América (Durán, 1581; Lozoya, 1999; Ximénez, 1615), lugar de donde pudieron dispersarse por acción humana hacia Chapultepec, otro importante jardín botánico de la época precolombina, en la Ciudad de México (Vovides, Linares, \& Bye, 2010).

Sin embargo, actualmente no se tiene registro de M. mexicana en inventarios florísticos de Morelos, Ciudad de México ni Estado de México (Calderón de Rzedowski \& Rzedowski, 2001; Cerros-Tlatilpa \& Espejo-Serna, 1998; Martínez de la Cruz, 2010; Martínez de la Cruz, 
Villaseñor, Aguilera Gómez, \& Rubí Arriaga, 2018; Rodríguez-Jiménez, Fernández-Nava, Arreguín-Sánchez, \& Rodríguez-Jiménez, 2005) que respalden los relatos históricos, pero se ha observado la presencia de dos árboles viejos y solitarios posiblemente de la especie, en los municipios de Malinalco (White Olascoaga, Juan Pérez, Cedillo Gutiérrez, \& Chávez Mejía, 2013) y Zumpahuacán en el Estado de México, que también podrían tener implicaciones sobre la distribución de M. mexicana.

En este sentido, la correcta identificación de los árboles de Yoloxóchitl mexiquenses resulta fundamental, en una especie que se encuentra amenazada de acuerdo con la NOM-059SEMARNAT-2010 (DOF, 2010) y que está catalogada como Vulnerable B1ab(iii,v), por la Unión Internacional para la Conservación de la Naturaleza (UICN) debido a la pérdida de su hábitat (Rivers, Martínez Salas, et al., 2016) y dificultad para propagarla por semilla (Osuna Fernández, 1997).

Aun cuando la caracterización morfológica ha permitido la discriminación de especies en otras magnolias (Vázquez-García, Gómez-Domínguez, et al., 2013; Vázquez-García, Muñiz-Castro, et al., 2013, 2012; Vázquez-García, Pérez-Farrera, et al., 2013), el empleo de marcadores moleculares ha probado su utilidad en este grupo por las muestras mínimas de tejido requerido y su capacidad discriminatoria entre poblaciones; tal es el caso de los marcadores RAPD (Polimorfismos de ADN Amplificados al Azar, por sus siglas en inglés), que se han mantenido vigentes, a pesar de su relativa baja reproducibilidad, por su simplicidad técnica (Kelleher \& Diskin, 2018; Larekeng, Dermawan, Iswoyo, \& Mustari, 2019; Sharma, Sharma, \& Kumar, 2018; Weising, Nybom, Wolff, \& Kahl, 2005), detección de un nivel alto de polimorfismo (Arumugam, Jayapriya, \& Sekar, 2019; Casarrubias-Carrillo et al., 2003; Mondragón-Jacobo, 2003) y su utilidad en la identificación genética de individuos (Rentaría Alcántara, 2007). Así, el objetivo del presente estudio fue establecer las relaciones moleculares y morfológicas existentes entre los árboles de Yoloxóchitl, presentes en Malinalco y Zumpahuacán, Estado de México, con individuos de M. mexicana de Zongolica, Veracruz.

\section{MATERIAL Y MÉTODOS}

\section{Material vegetal}

Se colectaron hojas jóvenes de dos árboles únicos maduros de Yoloxóchitl, uno en el municipio de Malinalco $\left(18^{\circ} 57^{\prime} 7.3^{\prime \prime} \mathrm{N}, 99^{\circ} 30^{\prime} 2.4^{\prime \prime} \mathrm{O}\right)$ y otro en el municipio de Zumpahuacán $\left(18^{\circ} 50^{\prime} 24.7^{\prime \prime} \mathrm{N}, 9^{\circ} 35^{\prime} 15.3^{\prime \prime} \mathrm{O}\right)$, Estado de México (fig. 1); así como hojas de diez árboles de M. mexicana, cuatro de éstos en la comunidad Acontla $\left(18^{\circ} 31^{\prime} 27.1^{\prime \prime} \mathrm{N}, 96^{\circ} 59^{\prime} 5.57^{\prime \prime} \mathrm{O}\right)$ y seis en La Quinta $\left(18^{\circ} 39^{\prime} 6.72^{\prime \prime} \mathrm{N}, 96^{\circ} 59^{\prime} 47.86^{\prime \prime} \mathrm{O}\right)$ en Zongolica, Veracruz. Para contar con elementos de referencia, se colectaron muestras de dos árboles de $M$. dealbata Zucc., en la comunidad de Atempa, también en Zongolica $\left(18^{\circ} 41^{\prime} 0.82^{\prime \prime} \mathrm{N}, 96^{\circ} 59^{\prime} 43.9^{\prime \prime} \mathrm{O}\right)$ y de cuatro árboles de $M$. grandiflora $\mathrm{L}$., en el municipio de Tenancingo $\left(18^{\circ} 58^{\prime} 6.22^{\prime \prime} \mathrm{N}, 99^{\circ} 36^{\prime} 45.84^{\prime \prime} \mathrm{O}\right)$, Estado de México, estos últimos se identificaron de acuerdo a sus características morfológicas según Hernánez-Cerda (1980) y Vázquez-García, Pérez-Farrera, Martínez-Meléndez, NievesHernández, \& Muñiz-Castro (2012). 

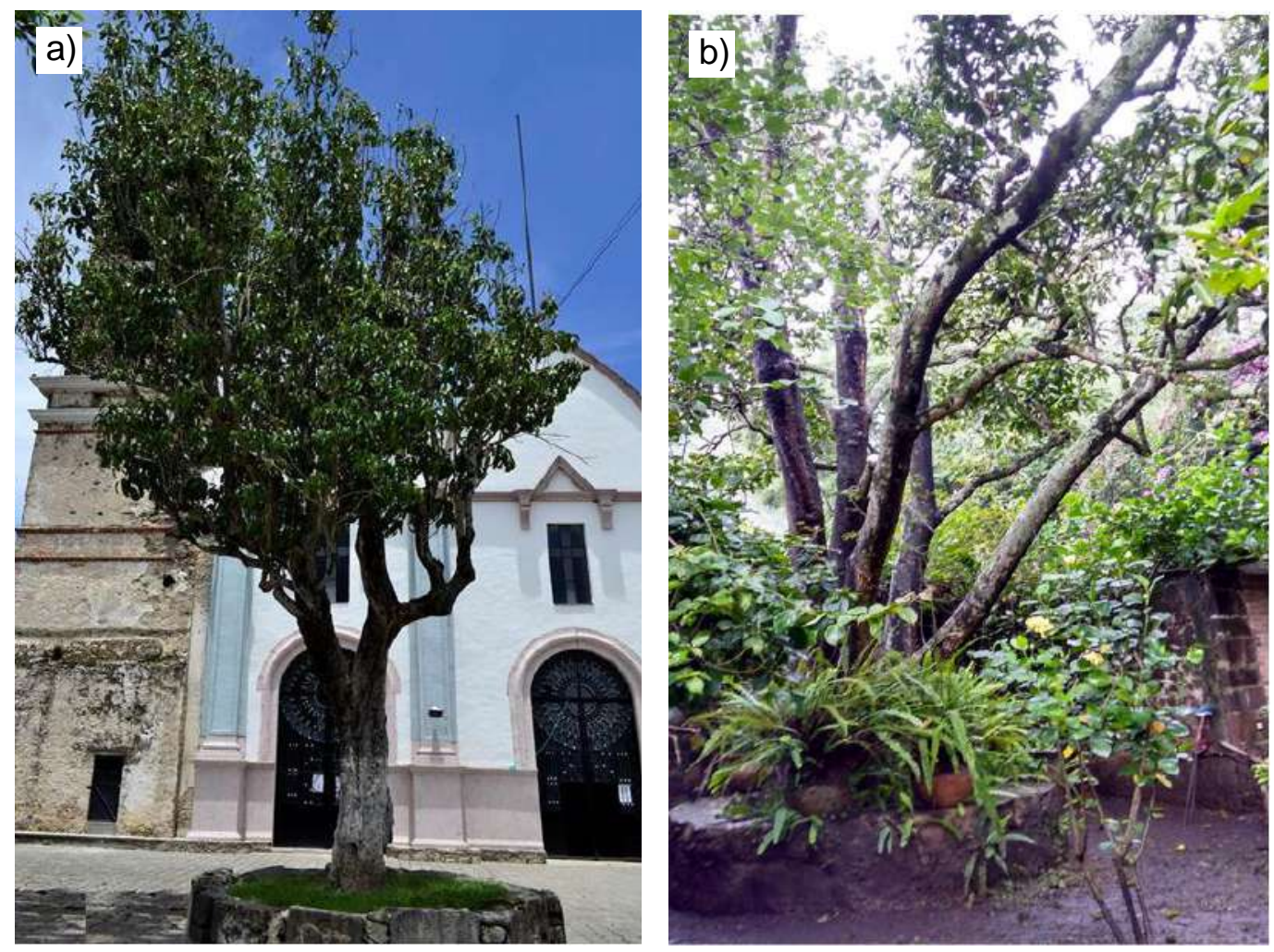

Fig. 1. Árboles de Yoloxóchitl, a) en el atrio de la iglesia de Zumpahuacán, b) en un predio particular en Malinalco, ambos en el Estado de México.

\section{Análisis molecular}

\section{Extracción de ADN}

Se utilizó el método CTAB al 2\% (Doyle \& Doyle, 1987), con modificación en la adición de $0.3 \mathrm{~g}$ de PVP (Polivinilpirrolidona) como agente precipitador de fenoles durante el macerado (Bermúdez-Guzmán et al., 2016). La calidad del ADN se evaluó por electroforesis en geles de agarosa al $1.5 \%$, a $90 \mathrm{~V}$ por 90 minutos con buffer tris-borato-EDTA (TBE) concentrado $0.5 \mathrm{x}$ (Fierro Fierro, 2007).

\section{Amplificación de fragmentos RAPD}

Se utilizaron 14 iniciadores RAPD (Operon Technologies Inc.) (cuadro 1), en un juego de 18 muestras de ADN de las magnolias bajo estudio (cuadro 2). La amplificación se realizó utilizando $11 \mu 1$ de $\mathrm{MyTaq}^{\mathrm{TM}}$ Mix (Bioline ${ }^{\circledR}$ ), $13 \mu 1$ de $\mathrm{H}_{2} \mathrm{O}$ destilada-desionizada libre de nucleasas Sigma ${ }^{\circledR}, 0.1 \mu \mathrm{mol}$ de cebador RAPD y $2 \mu \mathrm{l}$ de extracción final de ADN (106 ng/ $\mu 1$ $\mathrm{ADN})$ para un volumen final de reacción de $26 \mu \mathrm{l}$. El programa de amplificación fue: desnaturalización inicial de 3 minutos a $94{ }^{\circ} \mathrm{C}$, seguido de 35 ciclos de desnaturalización por 1 minuto a $94{ }^{\circ} \mathrm{C}$, alineación por 1 minuto a $36^{\circ} \mathrm{C}$ y extensión por 2 minutos a $72{ }^{\circ} \mathrm{C}$; y un ciclo de extensión final de 7 minutos a $72{ }^{\circ} \mathrm{C}$. 
Cuadro 1. Secuencia de los iniciadores RAPD utilizados en este estudio.

\begin{tabular}{ccc}
\hline Núm. & RAPD & Secuencia \\
\hline 1 & OPA6 & 5'-GGTCCCTGAC-3' \\
2 & OPA7 & 5'-GAAACGGGTG-3' \\
3 & OPA8 & 5'-GTGACGTAGG-3' \\
4 & OPA10 & 5'-GTGATCGCAG-3' \\
5 & OPA13 & 5'-CAGCACCCAC-3' \\
6 & OPA15 & 5'-TTCCGAACCC-3' \\
7 & OPA16 & 5'-AGCCAGCGAA-3' \\
8 & OPB1 & 5'-GTTTCGCTCC-3' \\
9 & OPB3 & 5'-CATCCCCCTG-3' \\
10 & OPB10 & 5'-CTGCTGGGAC-3' \\
11 & OPB17 & 5'-AGGGAACGAG-3' \\
12 & OPB19 & 5'-ACCCCCGAAG-3' \\
13 & E18 & 5'-GGACTGCAGA-3' \\
14 & C08 & 5'-TGGACCGGTG-3' \\
\hline
\end{tabular}

Los productos amplificados se separaron por electroforesis en geles de agarosa al $1.5 \%$ en amortiguador TBE $0.5 \mathrm{x}$, en cámara de electroforesis Cleaver®. Los geles corrieron durante 10 horas a $70 \mathrm{~V}$. Para el análisis de los marcadores RAPD, cada banda revelada fue considerada como un locus y se marcó con 1 la presencia y con 0 la ausencia de una banda en particular.

\section{Análisis estadístico}

De los amplicones revelados en los geles con cada cebador se construyó una matriz básica de datos (MBD) y con esta información se analizó la eficiencia de cada cebador RAPD al calcular el Contenido de Información Polimórfica (PIC) (Laurentin \& Karlovsky, 2007) y el Poder de Resolución (RP) (Prevost \& Wilkinson, 1999).

Con el cálculo de distancia genética de Dice (Dice, 1945; Nei \& Li, 1979) y el método de agrupación Neighbour-joining (Saitou \& Nei, 1987), se estimó la relación entre las muestras evaluadas, al aplicar un remuestreo con reemplazo (Bootstrap) de los caracteres en la matriz de datos de 1,000 corridas, por medio del programa FreeTree (Pavlicek, Hrda, \& Flegr, 1999) y se eligió el dendrograma de mayor concenso, que se visualizó por medio del programa FigTree (Page, 2001).

\section{Análisis morfológico}

Para los árboles de Yoloxóchitl del Estado de México y Veracruz, se registró información fenológica y se recabaron datos morfológicos de descriptores discriminantes entre especies de magnolias de la sección Talauma a saber: estructura del árbol (altura y número de troncos principales), hoja (presencia o ausencia de pubescencia abaxial, forma, largo del peciolo, largo y ancho de la lámina), flor (cantidad, coloración, largo y ancho de los pétalos, así como número y tamaño de los estambres) y fruto (tamaño, presencia o ausencia de pubescencia y número de carpelos); sin embargo, es necesario señalar que la cantidad de flores, frutos y hojas analizados es reducido y diferente para cada caso (cuadro 4), debido a las restricciones puestas por habitantes en las zonas de colecta, en virtud de la importancia socio-cultural, e incluso carácter sagrado (en el caso de Zumpahuacán) que poseen estos árboles; así, no se aplicó tratamiento estadístico a los datos, el análisis se limitó a los rasgos observados y medidos. 
Cuadro 2. Muestras del género Magnolia evaluados en análisis molecular.

\begin{tabular}{cccl}
\hline Núm. & Clave & Especie & \multicolumn{1}{c}{ Sitio de colecta } \\
\hline 1 & Md1 & M. dealbata & Atempa, Zongolica, Veracruz. \\
2 & Md2 & & Santo Desierto, Tenancingo, Edo. Mex. \\
\hline 3 & MS1 & & \\
4 & MS2 & M. grandiflora & Santa Ana, Tenancingo, Edo. Mex. \\
5 & MC1 & & Malinalco, Edo. Mex. \\
6 & MC2 & & \\
\hline 7 & Mali & Magnolia sp.* & Zumpahuacán, Edo. Mex. \\
8 & Zum & & La Quinta, Zongolica, Veracruz. \\
\hline 9 & Mm1 & & \\
10 & Mm2 & & Acontla, Zongolica, Veracruz. \\
11 & Mm3 & & \\
12 & Mm4 & & \\
13 & Mm5 & M. mexicana & \\
14 & Mm6 & & La Quinta, Zongolica, Veracruz. \\
16 & Mm7 & & \\
17 & Mm9 & & \\
18 & Mm10 & & \\
\hline
\end{tabular}

* Árboles de Yoloxóchitl solitarios del Estado de México para lo que está en duda su identidad específica.

\section{RESUlTADOS}

\section{Efectividad de los cebadores RAPD}

Con los 14 cebadores evaluados se amplificaron 205 bandas, con valores máximo y mínimo por cebador de 25 y nueve bandas respectivamente (cuadro 3). Los cebadores OPA7, OPA8 y E18 mostraron el mayor porcentaje de polimorfismo (100\%) y los cebadores OPB10 y OPB19 los más bajos (70 y 77.7 respectivamente).

Se obtuvo un valor PIC promedio de O.30, con un máximo de 0.41 y mínimo de 0.20 ; los cebadores con los valores PIC más elevados fueron el OPA7 (0.41), OPA8 (0.35) y E18 (0.38). También se registró un valor RP promedio de 5.42, con un máximo de 10.77 y mínimo de 0.33 , los cebadores con mayor valor RP fueron el OPA7 (8.55), OPA8 (10.77) y C08 (8.55). El cebador OPA7 mostró los valores PIC y RP más elevados.

\section{Relaciones genéticas entre las muestras de Magnolia spp.}

En el dendrograma derivado del análisis de agrupamiento (fig. 2), el empleo de las especies $M$. dealbata y $M$. grandiflora como referencia o control mostró su utilidad al separar claramente estas dos especies, con valores bootstrap del $100 \%$, en dos conjuntos diferentes al correspondiente de "Yoloxóchitl" que agrupó todas las muestras de M. mexicana (Mm1Mm10) con las de los árboles de Zumpahuacán (Zum) y Malinalco (Mali). 
Cuadro 3. Parámetros descriptivos de los cebadores RAPD utilizados.

\begin{tabular}{cccccc}
\hline Clave & $\mathbf{N B}^{\mathrm{a}}$ & $\mathbf{N B P}^{\mathrm{b}}$ & $\mathbf{\% ~ P o l}^{\mathrm{c}}$ & $\mathbf{P I C}^{\mathrm{d}}$ & $\mathbf{R P}^{\mathrm{f}}$ \\
\hline E18 & 12 & 12 & 100 & 0.38 & 6.88 \\
C08 & 18 & 17 & 94.4 & 0.31 & 8.55 \\
OPA6 & 14 & 13 & 92.8 & 0.35 & 7.44 \\
OPA7 & 17 & 17 & 100 & 0.41 & 10.77 \\
OPA8 & 16 & 16 & 100 & 0.35 & 8.55 \\
OPA10 & 14 & 13 & 92.9 & 0.28 & 5.66 \\
OPA13 & 20 & 18 & 90 & 0.25 & 6.66 \\
OPA15 & 25 & 21 & 84 & 0.24 & 7.77 \\
OPA16 & 14 & 13 & 92.8 & 0.32 & 2.22 \\
OPB1 & 12 & 10 & 83.3 & 0.29 & 0.66 \\
OPB3 & 15 & 12 & 80 & 0.22 & 5.11 \\
OPB10 & 10 & 7 & 70 & 0.20 & 2.11 \\
OPB17 & 9 & 8 & 88.8 & 0.35 & 0.33 \\
OPB19 & 9 & 7 & 77.7 & 0.28 & 3.22 \\
TOTAL & $\mathbf{2 0 5}$ & $\mathbf{1 8 4}$ & & $\mathbf{4 . 2 3}$ & $\mathbf{7 6}$ \\
Promedio & $\mathbf{1 4 . 6 4}$ & $\mathbf{1 3 . 1 4}$ & $\mathbf{8 9 . 0 5}$ & $\mathbf{0 . 3 0}$ & $\mathbf{5 . 4 2}$ \\
Máximo & 25 & 21 & 100 & 0.41 & 10.77 \\
Mínimo & 9 & 7 & 70 & 0.20 & 0.33 \\
\hline
\end{tabular}

${ }^{\mathrm{a}}$ Número de bandas. ${ }^{\mathrm{b}}$ Número de bandas polimórficas. ${ }^{\mathrm{c}}$ Porcentaje de polimorfismos.

${ }^{\mathrm{d}}$ Contenido de información polimórfica. ${ }^{\mathrm{e}}$ Índice del marcador. ${ }^{\mathrm{f}}$ Poder de resolución.

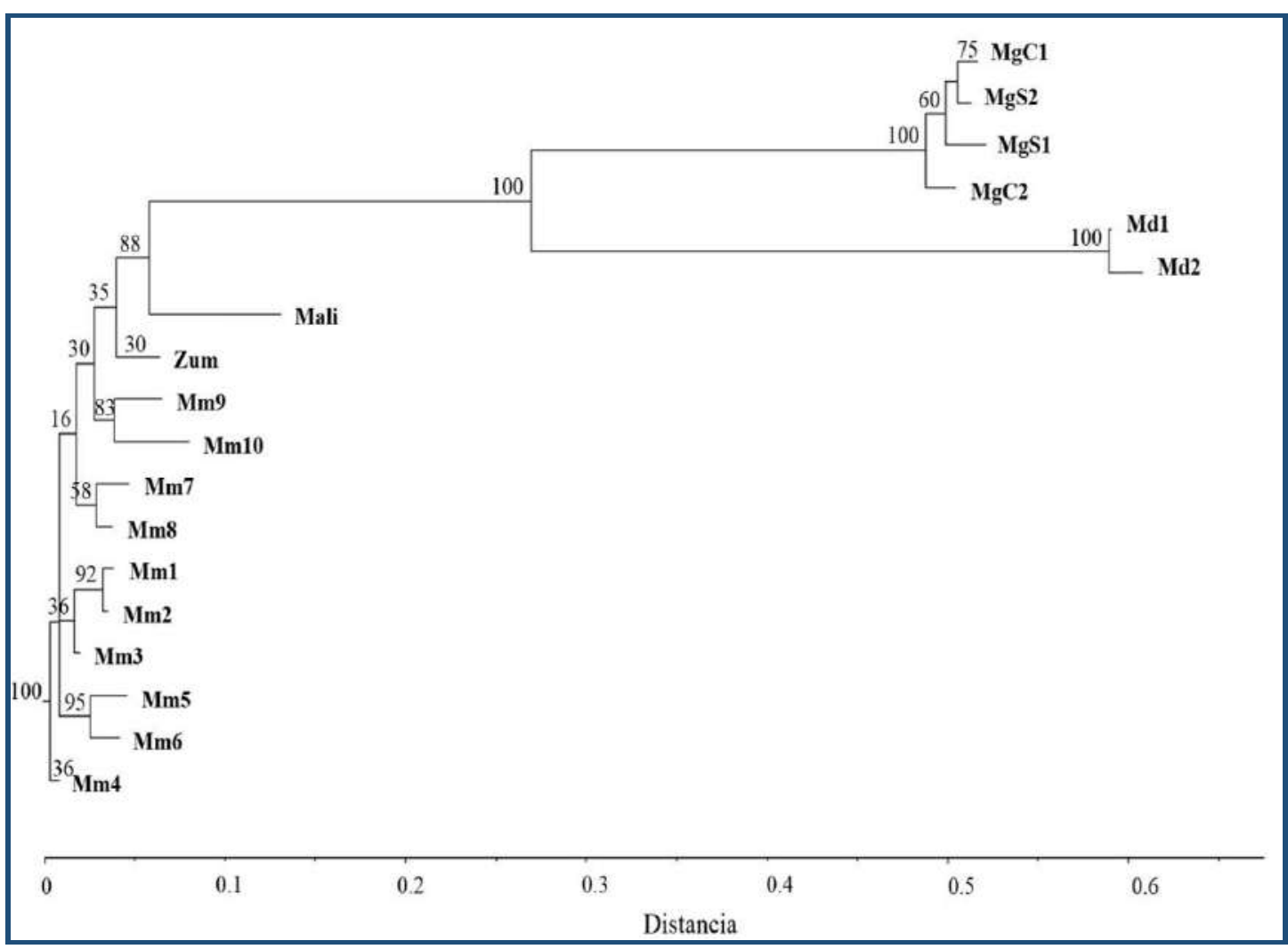

Fig. 2. Dendrograma de 18 muestras de Magnolia spp., con 14 cebadores RAPD por el método Neighbour Joining y distancia genética de Dice, los números encima de cada nodo indican valores bootstrap (1000 remuestreos). 
Dentro del grupo Yoloxóchitl, se observaron los individuos de Zumpahuacán y Malinalco posicionados espacialmente al extremo del conjunto con valores bootstrap de 30 y $88 \%$. Así mismo, se observó una similitud superior al $90 \%$ entre los individuos de Veracruz y el de Zumpahuacán, y de $87 \%$ de éstos con el correspondiente de Malinalco. La variación de similitud entre las poblaciones de Veracruz y los árboles mexiquenses fue de aproximadamente $7 \%$.

Se observó que, dentro del conjunto formado por M. mexicana, las muestras que se colectaron en Acontla aparecen en el extremo inferior (muestras Mm4, Mm5 y Mm6), por encima de ellas las que se colectaron en La Quinta (muestras Mm1, Mm2, Mm3, Mm8, Mm7, Mm9 y Mm10) y al extremo superior de todo el grupo, las muestras del Estado de México.

\section{Comparación morfológica de Yoloxóchitl}

Se observó aproximadamente un $77 \%$ de variación morfológica entre los individuos de Yoloxóchitl provenientes de Veracruz y los del Estado de México, y sólo cuatro caracteres (pubescencia abaxial de la hoja, perianto, color de los pétalos y pubescencia del polifolículo del fruto), fueron constantes en los tres tipos de Yoloxóchitl (cuadro 4 y fig. 3).

El ejemplar de Zumpahuacán guarda mayor relación morfológica con M. mexicana con la presencia de un solo fuste principal, similar número de carpelos del fruto, así como similar número y tamaño de los estambres y difirió en la altura del árbol, forma de la hoja, tamaño de las hojas, tamaño de los pétalos, forma y tamaño del fruto, con igual fenología; mientras que el ejemplar de Malinalco difirió en el número de troncos principales, tamaño del peciolo, forma de la hoja, tamaño de la hoja, número y tamaño de los estambres y número de carpelos, además de fenología diferente.

Así mismo, entre los ejemplares de Malinalco y Zumpahuacán se observó variación en el número de troncos principales, tamaño del peciolo, tamaño de la hoja, número de estambres, forma del fruto, número de carpelos y diferencias fenológicas.

\section{DISCUSIÓN}

Los marcadores RAPD utilizados mostraron en su mayoría valores PIC superiores a $0.25 \mathrm{y}$ ninguno tuvo valores por debajo de 0.15 , considerándose entonces como altamente informativos de acuerdo con Laurentin \& Karlovsky (2007); además, por el porcentaje de polimorfismos detectados, los marcadores en conjunto se consideraron eficientes y útiles para la caracterización de genotipos de Magnolia spp.

Así mismo, el valor RP se utilizó como una medida de la capacidad de cada cebador para distinguir entre genotipos (Prevost \& Wilkinson, 1999), por lo que, al obtener los valores RP más elevados, los cebadores E18, C08, OPA7 y OPA8 denotaron la mayor capacidad discriminante entre los genotipos de Magnolia spp., en particular, el cebador OPA7, al mostrar concordancia entre sus valores PIC y RP, sería el más recomendable para trabajar con este grupo botánico.

La habilidad observada de los RAPDs para separar muestras de acuerdo con su origen geográfico se ha reportado en otras especies (Casarrubias-Carrillo et al., 2003; JacintoHernández, Garza-García, Garza-García, \& Bernal-Lugo, 2014) y podría deberse a la participación de algunos genes en la adaptación a diferentes condiciones climáticas (Casarrubias-Carrillo et al., 2003); en el caso de los individuos de Zongolica, se observó la separación por origen aun cuando no son evidentes diferencias ambientales o geográficas entre los sitios de colecta; sin embargo, la existencia de factores genéticos asociados al lugar de origen ya se han reportado para la misma especie en la misma zona de estudio (MedranoHernández, Rodríguez de la O, Reyes-Trejo, \& Peña-Ortega, 2017). 
Cuadro 4. Caracteres morfológicos de ejemplares de Yoloxóchitl del Estado de México y Veracruz.

\begin{tabular}{|c|c|c|c|c|}
\hline & Caracteres morfológicos & $\begin{array}{l}\text { M. mexicana de } \\
\text { Veracruz }\end{array}$ & $\begin{array}{l}\text { Magnolia sp. de } \\
\text { Zumpahuacán }\end{array}$ & $\begin{array}{l}\text { Magnolia sp. de } \\
\text { Malinalco }\end{array}$ \\
\hline \multirow{2}{*}{$\begin{array}{l}\overrightarrow{8} \\
\text { 妾 }\end{array}$} & Altura aproximada (m) & 30 & 10 & 10 \\
\hline & Número de troncos principales & 1 & 1 & 5 \\
\hline \multirow{5}{*}{$\frac{\pi}{2}$} & Forma de la hoja & $\begin{array}{c}\text { Oblongas o elípticas, base } \\
\text { aguda }\end{array}$ & $\begin{array}{c}\text { Oblongas o elípticas, base } \\
\text { subobtusa }\end{array}$ & $\begin{array}{l}\text { Oblongas o elípticas, } \\
\text { base subobtusa }\end{array}$ \\
\hline & Pecíolo (cm) & $6.5-9.2$ & $6.8-8.8$ & $2.6-7.6$ \\
\hline & Longitud de la hoja (cm) & $17.7-49.5$ & $11.8-23.8$ & $8.4-19.5$ \\
\hline & Ancho de la hoja $(\mathrm{cm})$ & $10.6-17$ & $6.7-8.8$ & $5.6-10.7$ \\
\hline & $\begin{array}{l}\text { Pubescencia abaxial de la hoja } \\
\mathrm{n}^{*}\end{array}$ & $\begin{array}{c}\text { Glabra } \\
30 \\
\end{array}$ & $\begin{array}{c}\text { Glabra } \\
22 \\
\end{array}$ & $\begin{array}{c}\text { Glabra } \\
25 \\
\end{array}$ \\
\hline \multirow{7}{*}{$\frac{\overrightarrow{0}}{\underline{I}}$} & Diámetro de la flor (cm) & $18-20$ & 16 & $12-17$ \\
\hline & Perianto & 3 sépalos, 6 pétalos & 3 sépalos, 6 pétalos & 3 sépalos, 6 pétalos \\
\hline & Tamaño de los pétalos $(\mathrm{cm})$ & $7.5-9.8 \times 3-6.5$ & $6.5-7.8 \times 3.2-4.1$ & $6.5-8.3 \times 3-6$ \\
\hline & Color de los pétalos & $\begin{array}{l}\text { Blanco cremoso teñido de } \\
\text { púrpura }\end{array}$ & $\begin{array}{l}\text { Blanco cremoso teñido de } \\
\text { púrpura }\end{array}$ & $\begin{array}{l}\text { Blanco cremoso teñido } \\
\text { de púrpura }\end{array}$ \\
\hline & Número de estambres & 183 & $121-184$ & $155-169$ \\
\hline & Tamaño de los estambres $(\mathrm{cm})$ & $1.3-1.4$ & 1.3 & $1.2-1.3$ \\
\hline & $\mathrm{n}$ & 2 & 2 & 3 \\
\hline \multirow{6}{*}{ 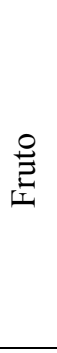 } & Forma del fruto & Ovoide a elipsoidal & Acorazonado & Ovoide a elipsoidal \\
\hline & Tamaño del fruto $(\mathrm{cm})$ & 15 & $12 * *$ & $10^{* *}$ \\
\hline & Número de carpelos & $38-50$ & $39-40$ & 35 \\
\hline & Pubescencia del polifolículo & Ligeramente pubescente & Ligeramente pubescente & Ligeramente pubescente \\
\hline & Longitud de la semilla (cm) & $1.4-1.7$ & $\mathrm{~s} / \mathrm{d}$ & $\mathrm{s} / \mathrm{d}$ \\
\hline & $\mathrm{n}$ & 4 & 2 & 1 \\
\hline \multirow{2}{*}{ 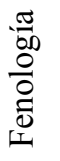 } & Floración & mayo - agosto & mayo - agosto & marzo - junio \\
\hline & $\begin{array}{l}\text { Fructificación } \\
\text { (frutos maduros) }\end{array}$ & febrero - abril & febrero - abril & julio - octubre \\
\hline
\end{tabular}

Notas: *n hace referencia al número de hojas, flores y frutos que se colectaron en cada caso, ${ }^{* *}$ Frutos inmaduros que a madurez no producen semillas. 
a)

Zongolica

Zumpahuacán

Malinalco

a) $50 \mathrm{~cm}$ haz envés

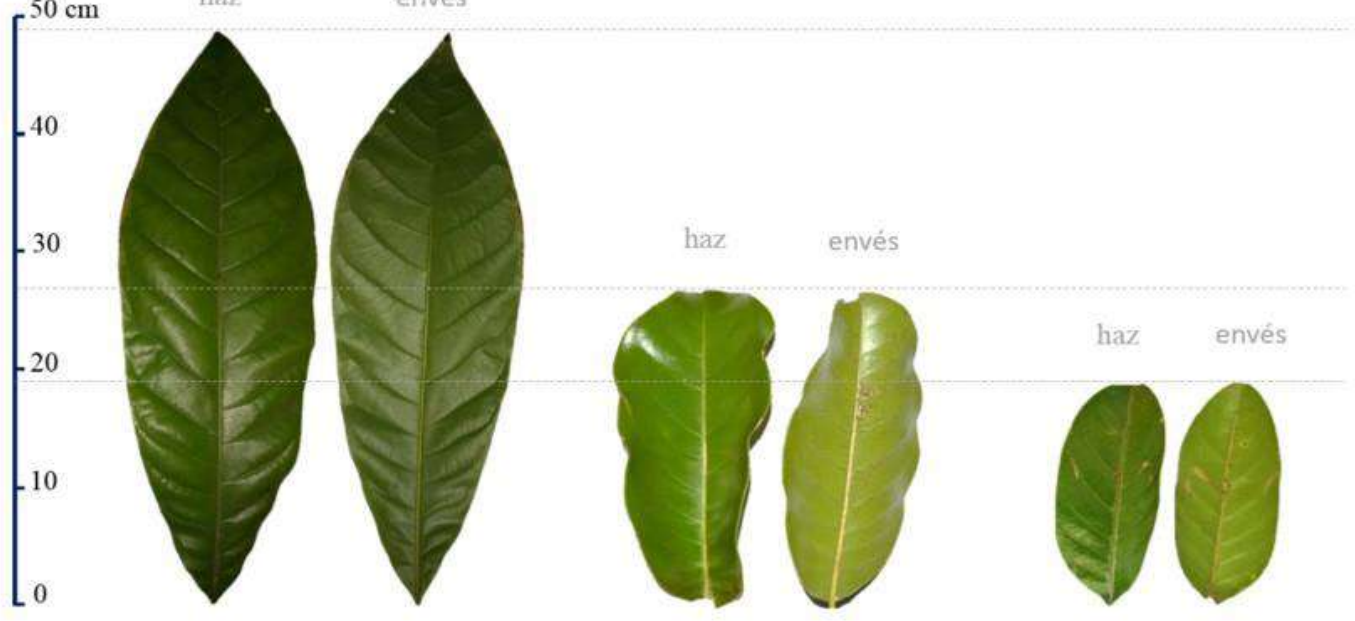

b)

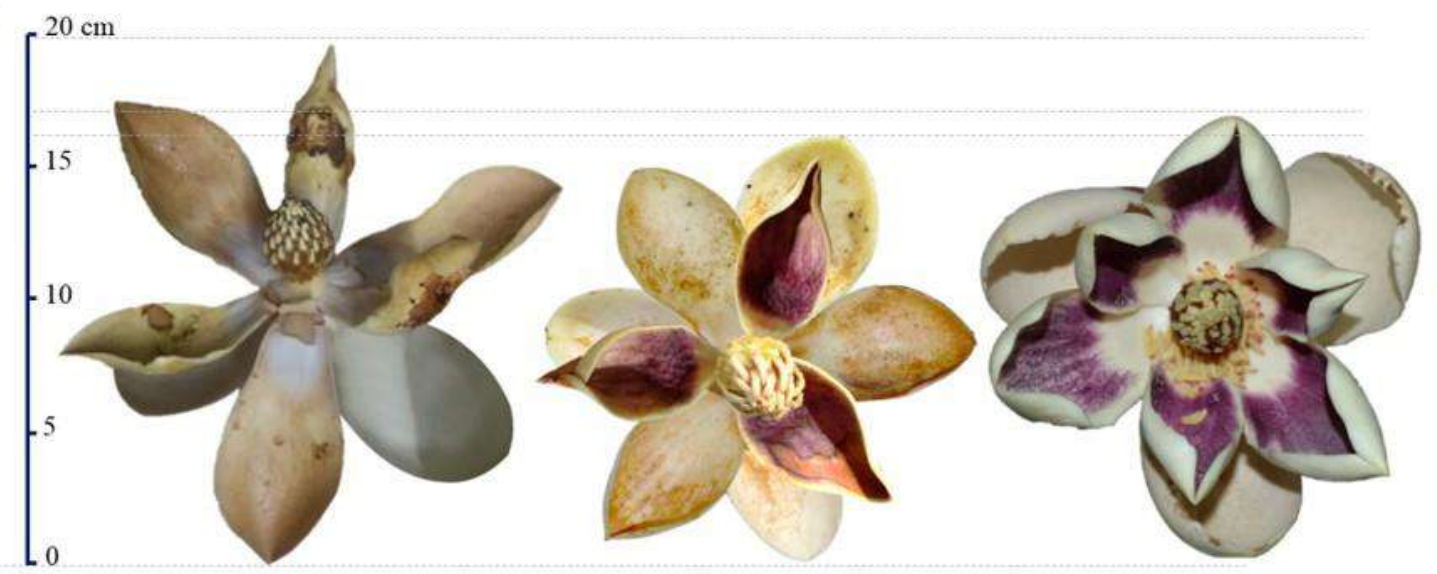

c)

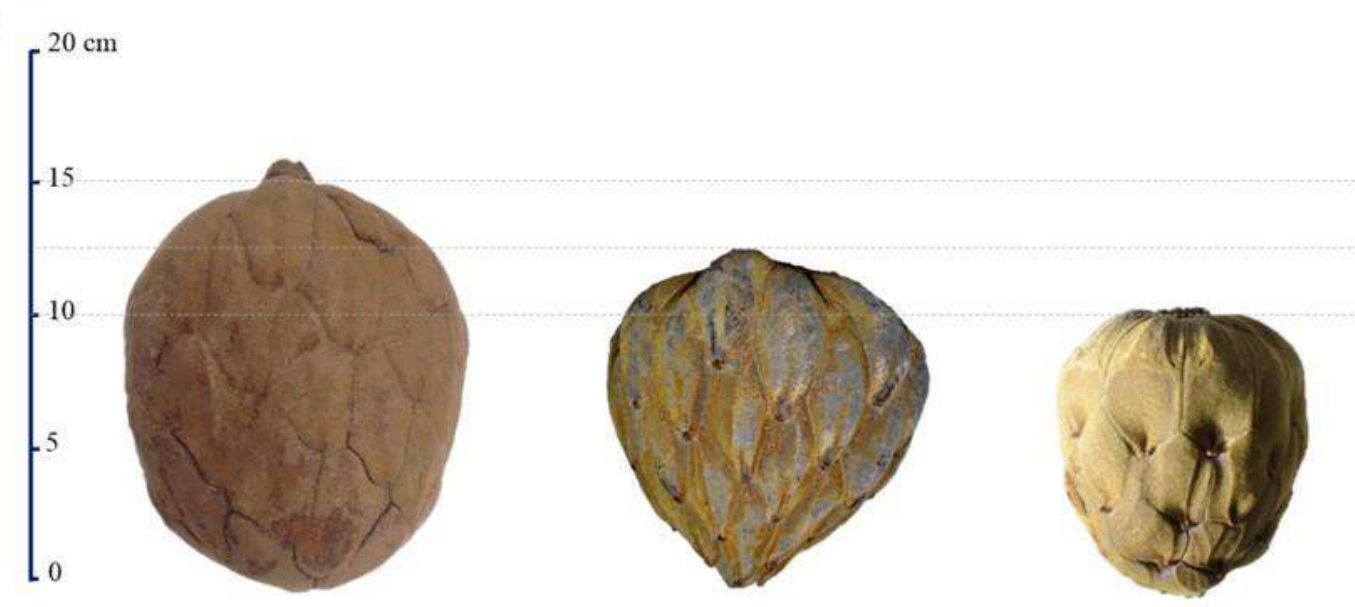

Fig. 3. Comparación de hoja (a), flor (b) y fruto (c) de los árboles de Yoloxóchitl de Zongolica, Zumpahuacán y Malinalco. 
La separación en dendrograma de las muestras de M. grandiflora (sección Magnolia) y $M$. dealbata (sección Macrophylla) en dos grupos distantes del correspondiente al de los Yoloxóchilt evidencia que los genotipos de Veracruz y los del Estado de México pertenecen a la misma la sección botánica (Talauma). Además, la topología del dendrograma, con los grupos M. dealbata y M. grandiflora ubicados por encima del grupo Yoloxóchitl, es coincidente con estudios filogenéticos en magnolias reportados por Azuma, García-Franco, Rico-Gray, \& Thien (2001) y Kim \& Suh (2013), quienes sugieren para la sección Talauma del género Magnolia, una divergencia evolutiva más temprana que las secciones Magnolia y Macrophylla.

Respecto al grupo Yoloxóchitl, la alta similitud observada entre los genotipos de M. mexicana y el de Zumpahuacán indicaría que pertenecen a la misma especie aunque su posición en el dendrograma no está fuertemente respaldada por el valor bootstrap (35\%), mientras que la mayor distancia observada con el individuo de Malinalco, respaldada por el valor de remuestreo $(88 \%)$, podría indicar que se trata de una especie diferente, sin embargo, al no tener como referencia otras especies de la misma sección botánica no fue claro el grado de separación que se esperaría para afirmarlo, sin embargo, en un estudio mediante ISSRs realizado por MuñizCastro, Castro-Félix, Carranza-Aranda, Santerre Lucas, \& Vázquez-García (2017), con $M$. pugana, M. pacifica y M. vallartensis de la sección Magnolia, encontraron una variación de sólo el $8 \%$ entre poblaciones de éstos tres taxa, similar a la encontrada en el presente estudio $(7 \%)$.

La variación morfológica observada entre $M$. mexicana respecto al individuo de Zumpahuacán (seis caracteres) y el de Malinalco (siete caracteres), sugiere también una diferenciación a nivel específico, ya que la reclasificación a nuevas especies de algunas poblaciones de M. mexicana ha resultado de variaciones morfológicas similares; por ejemplo, la reclasificación a $M$. perezfarrerae refirió variación en seis caracteres (Vázquez-García, Gómez-Domínguez, et al., 2013), la reclasificación a M. lacandonica consideró cuatro caracteres (Vázquez-García, PérezFarrera, et al., 2013), la reclasificación a M. zoquepopolucae contempló siete caracteres (Vázquez-García, De Castro-Arce, et al., 2012) y similar número de diferencias se consideraron en el resto de especies mexicanas de la sección Talauma recientemente descritas (VázquezGarcía, Muñiz-Castro, et al., 2013, 2012).

Algunos autores señalan la posibilidad de que las variaciones observadas se deban a intervención humana, como lo es la emisión de varios fustes por efecto de corte del tronco principal en edad temprana, ya documentado para M. sprengeri (Kang \& Ejder, 2011); o bien, sean producto de la plasticidad fenotípica propia de una especie como respuesta adaptativa a un nuevo hábitat (Sultan, 2000). Así, si se considera que los árboles de Yoloxóchitl en el Estado de México fueron traídos directamente o son descendientes de aquellos que se presume provinieron de Veracruz, entonces los contrastes fenotípicos entre ellos podrían ser resultado de su plasticidad a la variación ambiental, toda vez que entre Malinalco, Zumpahuacán y Zongolica existen diferencias de altitud, intervalo de temperatura y nivel de precipitación pluvial de consideración (INEGI, 2009c, 2009a, 2009b).

Ejemplos de plasticidad fenotípica en magnolias se han reportado como pequeñas variaciones morfológicas en especies como M. iltisana en la que se observaron cambios en la biomasa de raíces y hojas en respuesta a variación de luz (Saldaña-Acosta, Meave, \& Sánchez-Velásquez, 2009) y en $M$. pugana que presentó diferencias significativas en el crecimiento de plántulas bajo distintas condiciones de luz y fertilidad del suelo (García Castro, Romo-Campos, Pereira, \& Gómez-Rubio, 2018); también se ha reportado variabilidad morfológica en color, tamaño y número de tépalos de las flores en $M$. wufengensis entre cultivares y una población silvestre (Wang et al., 2017) y variación en la forma de las hojas y coloración de las flores entre ejemplares solitarios y poblaciones tanto silvestres como cultivadas de M. sprengeri (Kang \& Ejder, 2011), en este último caso, las diferencias morfológicas pueden ser tan marcadas que los autores consideran que la variación en la forma y tamaño de las hojas, así como en el número de tépalos y coloración de las flores entre árboles de una población o meta población de magnolias 
no debería tener valor significativo como caracter taxonómico ni ser una razón para el otorgamiento del estatus de especie o subespecie, coincidiendo con lo mencionado por Vázquez-García, Domínguez-Yescas, Pedraza-Ruiz, Sánchez-González, \& Muñiz-Castro (2015) en este mismo sentido.

Sería necesario realizar experimentos de establecimiento entre las áreas de estudio para determinar hasta qué punto se puede asumir que las diferencias morfológicas encontradas, más allá de las que distinguen un género, son sólo debidas al ambiente, lo que representaría reconsiderar la reclasificación de nuevas especies; sin embargo, se ha observado que las magnolias en México presentan una marcada especiación alopátrica, en donde las diferencias ambientales o geográficas tienen gran importancia en la separación de poblaciones en especies diferentes (Cruz-Durán, Vega-Flores, \& Jiménez-Ramírez, 2008; Vázquez-García, 1994; Vázquez-García et al., 2015); además, el status actual de M. mexicana como especie amenazada, sugiere que no es una especie con gran capacidad plástica, ya que de acuerdo con Sultan (2000), las especies con poca plasticidad para mantener la reproducción y crecimiento, se restringen a nichos especializados y están en particular riesgo de extinción.

Entonces, la posible ausencia de efecto de plasticidad, sugiere que, por la variación morfológica observada, los Yoloxóchitl de Malinalco y Zumpahuacán serían especies distintas a $M$. mexicana y a las demás especies recientemente reclasificadas de la sección Talauma, al diferir de éstas últimas en similar número de caracteres, por ejemplo, Magnolia sp. de Zumpahuacán difiere en cuatro caracteres de flor y fruto con $M$. zoquepopolucae (Vázquez-García, De CastroArce, et al., 2012) y en ocho caracteres de hoja, flor y fruto con M. jaliscana (Vázquez-García, Muñiz-Castro, et al., 2012); mientras que Magnolia sp. de Malinalco difiere en cinco y seis caracteres con estas mismas especies.

El origen de los Yoloxóchitl mexiquenses es incierto, ya que las especies de magnolias geográficamente más cercanas (M. krusei, M. vazquezii y $M$. guerrerensis) pertenecen a la sección Magnolia que es morfológicamente distinguible de la sección Talauma (Cruz-Durán et al., 2008; Jiménez-Ramírez, Vega-Flores, Cruz-Durán, \& Vázquez-García, 2007; VázquezGarcía, Muñiz-Castro, et al., 2013), de la cual no existen registros en inventarios florísticos realizados en la zona de estudio (Calderón de Rzedowski \& Rzedowski, 2001; Cerros-Tlatilpa \& Espejo-Serna, 1998; López Patiño, López-Sandoval, Beltrán-Retis, \& Aguilera-Gómez, 2018; Martínez de la Cruz, 2010; Martínez de la Cruz et al., 2018; Rodríguez-Jiménez et al., 2005).

En concordancia con los relatos históricos, podría tratarse de ejemplares introducidos a partir de poblaciones de especies en Veracruz ya inexistentes o bien ser ejemplares únicos de especies nativas ya desaparecidas, ambas suposiciones se soportan en el hecho de que ninguno de los dos ejemplares mexiquenses analizados produce semillas viables (observación directa y com. pers. con pobladores), incapacidad que puede estar asociada a diferentes factores como la inexistencia de polinizadores específicos o autoincompatibilidad; este tipo de esterilidad de las semillas se ha observado de forma común en árboles silvestres solitarios de M. sprengeri debido a la imposibilidad de una polinización cruzada por falta de otros ejemplares cercanos de la misma especie y se sabe que no es posible la autofecundación en dicha especie aún si se trata de flores distintas del mismo árbol (Kang \& Ejder, 2011), también Hirayama, Ishida, \& Tomaru (2005) reportaron que se reduce grandemente la producción de semilla en $M$. stellata por efecto de la geitonogamia; resultados similares se reportaron también para $M$. obovata (Ishida, Yoshimaru, \& Ito, 2003); lo anterior sugiere que los árboles de Yoloxóchitl de Malinalco y Zumpahuacán no producen semillas viables debido a la falta de polinización cruzada ante la ausencia de individuos cercanos de la misma especie.

Si se considera que las magnolias presentan marcada especiación alopátrica, que M. mexicana es una especie de estrecha capacidad plástica y que las diferencias morfológicas encontradas coinciden con aquellas que han posibilitado la reclasificación a nuevas especies, se sugiere que 
los árboles de Yoloxóchitl en Malinalco y Zumpahuacán pertenecen a otras especies, que, por razones de su historia particular, se encuentran aislados.

\section{CONCLUSIONES}

La evidencia molecular obtenida indica que los árboles de Yoloxóchitl en Malinalco y Zumpahuacán pertenecen a la sección Talauma, pero, debido a la variación morfológica observada entre ellos y en relación con M. mexicana, cabe la posibilidad de que se trate de dos especies distintas aún no descritas.

\section{LITERATURA CITADA}

Arumugam, T., Jayapriya, G., \& Sekar, T. (2019). Molecular fingerprinting of the Indian medicinal plant Strychnos minor Dennst. Biotechnology Reports, 21(2018), 1-7. https://doi.org/10.1016/j.btre.2019.e00318

Azuma, H., García-Franco, J. G., Rico-Gray, V., \& Thien, L. B. (2001). Molecular phylogeny of the Magnoliaceae: The biogeography of tropical and temperate disjunctions. American Journal of Botany, 88(12), 2275-2285. https://doi.org/10.2307/3558389

Bermúdez-Guzmán, M. D. J., Guzmán-González, S., Orozco-Santos, M., Velázquez-Monreal, J. J., Buenrostro-Nava, M. T., \& Michel-López, C. Y. (2016). Optimización de un protocolo para aislamiento de DNA de hojas de Saccharum officinarum. Revista Mexicana de Ciencias Agrícolas, 7(4), 897-910. https://doi.org/10.29312/remexca.v7i4.263

Calderón de Rzedowski, G., \& Rzedowski, J. (2001). Flora fanerogámica del Valle de México (2a ed.). México, D.F.: Instituto de Ecología A. C. y Comisión Nacional para el Conocimiento y Uso de la Biodiversidad.

Casarrubias-Carrillo, U., González-Chavira, M. M., Cruz-Hernández, A., Cárdenas-Soriano, E., Nieto-Ángel, D., \& Guevara-González, R. G. (2003). Variabilidad genetica de Colletotrichum gloesporioides (Penz.) Penz y Sacc. aislado de frutos de papaya (Carica papaya L.) mediante el uso de marcadores moleculares RAPD. Revista Mexicana de Fitopatologia, 21(3), 338-345.

Cerros-Tlatilpa, R., \& Espejo-Serna, A. (1998). Contribución al estudio florístico de los cerros El Sombrerito y Las Mariposas ( Zoapapalotl ) en el municipio de Tlayacapan, Morelos. Polibotánica, (8), 29-46.

Cruz-Durán, R., Vega-Flores, K., \& Jiménez-Ramírez, J. (2008). Magnolia vazquezii (Magnoliaceae), una especie nueva del Estado de Guerrero, México. Novon: A Journal for Botanical Nomenclature, 18(1), 21-24. https://doi.org/10.3417/2005096

de Candolle, A. P. (1818). Regni Vegetabilis Systema Naturale. Retrieved from http://bibdigital.rjb.csic.es/spa/Libro.php?Libro=2675\&Hojas=

Dice, L. R. (1945). Measures of the amount of ecologic association between species. Ecology, 26(3), 297-302.

DOF. Norma Oficial Mexicana NOM-059-SEMARNAT-2010, protección ambiental-especies nativas de México de flora y fauna silvestres-Categorías de riesgo y especificaciones para su inclusión, exclusión o cambio-lista de especies en riesgo., (2010).

Doyle, J. J., \& Doyle, J. L. (1987). A rapid DNA isolation procedure for small quantities of fresh leaf tissue. Phytochemical Bulletin, 19(1), 11-15. Retrieved from https://webpages.uncc.edu/ jweller2/pages/BINF8350f2011/BINF8350_Readings/Doy le_plantDNAextractCTAB_1987.pdf

Durán, D. (1581). Historia de las Indias de Nueva España e Islas de tierra firme. Retrieved from http://bdh-rd.bne.es/viewer.vm?id=0000169486\&page $=1$

Fierro Fierro, F. (2007). Elecroforesis de ADN. In Herramientas moleculares aplicadas en ecología: aspectos teóricos y prácticos (1a ed.). México, D.F.: Secretaría del Meio Ambiente y Recursos Naturales, Instituto Nacional de Ecología y Cambio Climático, 
Universidad Autónoma Metropolitana-Iztapalapa.

García Castro, K. D., Romo-Campos, R. de L., Pereira, C. J., \& Gómez-Rubio, R. (2018). Tasa relativa de crecimiento en plántulas de dos poblaciones de Magnolia pugana (Magnoliaceae) en distintos niveles de luz y fertilidad del suelo. Revista de Biología Tropical, 66(2), 622. https://doi.org/10.15517/rbt.v66i2.33394

Gómez-Domínguez, H., Pérez-Farrera, Mi. Á., Vázquez-García, J. A., Sahagún-Godínez, E., \& Muñiz-Castro, M. Á. (2017). Magnolia montebelloensis, a new species in section Magnolia from Lagunas de Montebello National Park, Chiapas, México, with a key to Magnoliaceae of Chiapas. Phytotaxa, 328(2), 101. https://doi.org/10.11646/phytotaxa.328.2.1

Hernánez-Cerda, M. E. (1980). Magnoliaceae. In Flora de Veracruz. https://doi.org/10.1142/9781938368356_0004

Hirayama, K., Ishida, K., \& Tomaru, N. (2005). Effects of pollen shortage and self-pollination on seed production of an endangered tree, Magnolia stellata. Annals of Botany, 95(6), 1009-1015. https://doi.org/10.1093/aob/mci107

INEGI. (2009a). Malinalco, México. Retrieved from https://ecitydoc.com/download/prontuariode-informacion-geografica-municipal-30_pdf

INEGI. (2009b). Zongolica, Veracruz de Ignacio de la Llave. Retrieved from http://www3.inegi.org.mx/contenidos/app/mexicocifras/ datos_geograficos/30/30201.pdf

INEGI. (2009c). Zumpahuacán, México. In Prontuario de información geográfica municipal de los Estados Unidos Mexicanos. Retrieved from http://www3.inegi.org.mx/contenidos/app/mexicocifras/datos_geograficos/15/ 15119.pdf

Ishida, K., Yoshimaru, H., \& Ito, H. (2003). Effects of geitonogamy on the seed set of Magnolia obovata Thunb. ( Magnoliaceae ). International Journal of Plant Sciences, 164(5), 729-735.

Jacinto-Hernández, C., Garza-García, R., Garza-García, D., \& Bernal-Lugo, I. (2014). Caracterización de germoplasma nativo de frijol con base en marcadores moleculares y atributos de calidad. Revista Mexicana de Ciencias Agrícolas, 5(2), 253-264. https://doi.org/10.29312/remexca.v5i2.964

Jiménez-Ramírez, J., Vega-Flores, K., Cruz-Durán, R., \& Vázquez-García, J. A. (2007). Magnolia guerrerensis (Magnoliaceae), una especie nueva del bosque mesófilo de montaña del estado de Guerrero, México. Botanical Sciences, 80, 73-76. https://doi.org/10.17129/botsci.1746

Kang, Y., \& Ejder, E. (2011). Magnolia sprengeri Pamp .: Morphological variation and geographical distribution. Plan Biosystems, 145(4), 906-923. https://doi.org/10.1080/11263504.2011.633352

Kelleher, C. T., \& Diskin, A. (2018). Assessing botanical gardens specimens as a genetic resource for the future conservation - a pilot study using Magnolia delavayi in the gardens of Ireland. Hortus Botanicus, 12(12), 151-159. https://doi.org/10.15393/j4.art.2017.3942

Kim, S., \& Suh, Y. (2013). Phylogeny of Magnoliaceae based on ten chloroplast DNA regions. Journal of Plant Biology, 56(5), 290-305. https://doi.org/10.1007/s12374-013-0111-9

Larekeng, S. H., Dermawan, R., Iswoyo, H., \& Mustari, K. (2019). RAPD primer screening for amplification on Katokkon pepper from Toraja, South Sulawesi, Indonesia. IOP Conference Series: Earth and Environmental Science, 270(1), 1-7. https://doi.org/10.1088/1755-1315/270/1/012023

Laurentin, H., \& Karlovsky, P. (2007). AFLP fingerprinting of sesame (Sesamum indicum L.) cultivars: Identification, genetic relationship and comparison of AFLP informativeness parameters. Genetic Resources and Crop Evolution, 54(7), 1437-1446. https://doi.org/10.1007/s10722-006-9128-y

López Patiño, E. J., López-Sandoval, J. A., Beltrán-Retis, A. S., \& Aguilera-Gómez, L. I. (2018). Composición de la flora arbórea en el área natural protegida TenancingoMalinalco-Zumpahuacán, Estado de México, México. Polibotánica, (34), 51-98. 
Lozano-Contreras, G. (1994). Dugandiodendron y Talauma (Magnoliaceae) en el Neotrópico. Bogotá: Academia Colombiana de Ciencias Exactas, Físicas y Naturales.

Lozoya, X. (1999). Yoloxóchitl. In Xiuhpatli, Herba Officinalis. México, D.F.: UNAM Dirección General de Publicaciones y Fomento Editorial.

Martínez de la Cruz, I. (2010). La flora y vegetación ruderal de Malinalco, Estado de México (Colegio de Postgraduados). Retrieved from http://www.remeri.org.mx/portal/ REMERI.jsp?id=oai:www.biblio.colpos.mx:10521/143

Martínez de la Cruz, I., Villaseñor, J. L., Aguilera Gómez, L. I., \& Rubí Arriaga, M. (2018). Angiospermas nativas documentadas en la literatura para el Estado de México, México. Acta Botánica Mexicana, 124, 135-217. https://doi.org/10.21829/abm124.2018.1273

Medrano-Hernández, J. M., Rodríguez de la O, J. L., Reyes-Trejo, B., \& Peña-Ortega, M. G. (2017). Molecular characterization using ISSR primers of Magnolia mexicana DC. from two regions in Zongolica, Veracruz, Mexico. Revista Chapingo Serie Ciencias

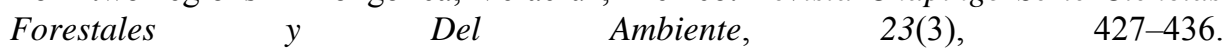
https://doi.org/10.5154/r.rchscfa.2017.03.019

Micheli, A. De. (2004). El largo camino hacia lacardiología mexicana de hoy. Gaceta Médica de México, 140, 346-352.

Mondragón-Jacobo, C. (2003). Caracterización molecular mediante RAPDs de una colección de nopal (Opuntia spp. Cactaceae) del centro de México, como base del mejoramiento genético. Revista Chapingo Serie Horticultura, 9(1), 97-105.

Muñiz-Castro, M. Á., Castro-Félix, P., Carranza-Aranda, A. S., Santerre Lucas, A., \& VázquezGarcía, J. A. (2017). Genetic population structure and diversity of Magnolia pacifica A.Vázquez species complex in southwestern Mexico inferred from ISSR markers. XIX International Botanical Congress, (July 17-21), 262. Shenzhen, China: XIX International Botanical Congress.

Nei, M., \& Li, W. H. (1979). Mathematical model for studying genetic variation in terms of restriction endonucleases. Proceedings of the National Academy of Sciences of the United States of America, 76(10), 5269-5273. Retrieved from http://www.ncbi.nlm.nih.gov/pubmed/291943\%0Ahttp://www.pubmedcentral.nih.gov/ articlerender.fcgi?artid=PMC413122

Osuna Fernández, H. R. (1997). Estructura y respuesta germinativa de semillas de plantas medicinales: Chiranthodendron pentadactylon y Talauma mexicana. Universidad Nacional Autónoma de México.

Page, R.D.M. (2001). TreeView. Retrieved from http:/taxonomy.zoology.gla.ac.uk/ $\mathrm{rod} / \mathrm{rod} . \mathrm{htm} \% 0 \mathrm{APala}$

Pavlicek, A., Hrda, S., \& Flegr, J. (1999). FreeTree-freeware program for construction of phylogenetic trees on the basis of distance data and bootstrap jackknife analysis of the tree robustness. Application in the RAPD analysis of genus Frenkelia. Folia Biologica, 45(3), 97-99. Retrieved from http://apps.isiknowledge.com/full_record.do?product $=$ WOS\&search_mode $=$ GeneralSearch\&qid $=2 \& S I D=3$ CncemegikaKEaCali8\&page $=2$ $9 \& \mathrm{doc}=1422$

Prevost, A., \& Wilkinson, M. J. (1999). A new system of comparing PCR primers applied to ISSR fingerprinting of potato cultivars. Theoretical and Applied Genetics, 98(1), 107112. https://doi.org/10.1007/s001220051046

Rentaría Alcántara, M. (2007). Breve revisión de los marcadores moleculares. In Ecología molecular (1a ed., pp. 541-566). Retrieved from https://micrositios.inecc.gob.mx/ publicaciones/libros/530/cap18.pdf

Rivers, M., Beech, E., Murphy, L., \& Oldfield, S. (2016). Magnoliaceae revised and extended. Richmond, UK: Botanic Gardens Conservation International.

Rivers, M., Martínez Salas, E., \& Samain, M. S. (2016). Magnolia mexicana, Yoloxóchitl. https://doi.org/10.2305/IUCN.UK.2016- 1.RLTS.T193977A2293105.en

Rodríguez-Jiménez, C., Fernández-Nava, R., Arreguín-Sánchez, M. de la L., \& RodríguezJiménez, A. (2005). Plantas vasculares endémicas de la cuenca del río Balsas, México. Polibotánica, (20), 73-99. 
Saitou, N., \& Nei, M. (1987). The Neighbor-joining method: a new method for reconstructing phylogenetic trees. Molecular Biology and Evolution, 4(4), 406-425. Retrieved from papers://92fd5174-9e31-4983-9b1c-5a79350234b8/Paper/p6217

Saldaña-Acosta, Á., Meave, J. A., \& Sánchez-Velásquez, L. R. (2009). Seedling biomass allocation and vital rates of cloud forest tree species: Responses to light in shade house conditions. Forest Ecology and Management, 258(7), 1650-1659. https://doi.org/10.1016/j.foreco.2009.07.027

Sessé, M., \& Mociño, J. M. (1894). Flora mexicana (2a ed.). Retrieved from http://bibdigital.rjb.csic.es/spa/Libro.php?Libro=2923\&Hojas=

Sharma, R., Sharma, S., \& Kumar, S. (2018). Pair-wise combinations of RAPD primers for diversity analysis with reference to protein and single primer RAPD in soybean. Annals of Agrarian Science, 16(3), 243-249. https://doi.org/10.1016/j.aasci.2018.03.002

Silva Rojas, H. V., Uribe Cortés, T. B., Aguirre Rayo, J. M., Martínez González, C. R., \& García Morales, S. (2015). Extracción de DNA y amplificación dde genes ribosomales, cloroplastos, mitocondriales y housekeeping (1a ed.). Texcoco, Estado de México: Colegio de Postgraduados, Campus Montecillo.

Sultan, S. E. (2000). Phenotypic plasticity for plant development, function and life history. Trends in Plant Science, 5(12), 537-542. https://doi.org/10.1016/S13601385(00)01797-0

Vázquez-García, J. A. (1994). Magnolia (Magnoliaceae) in Mexico and Central America: A Synopsis. Brittonia, 46(1), 1. https://doi.org/10.2307/2807454

Vázquez-García, J. A., De Castro-Arce, E., Muñiz-Castro, M. Á., \& Cházaro-Basañez, M. de J. (2012). Magnolia zoquepopolucae. Phytotaxa, 55(May), 51-55.

Vázquez-García, J. A., Domínguez-Yescas, R., Pedraza-Ruiz, R., Sánchez-González, A., \& Muñiz-Castro, M. Á. (2015). Magnolia rzedowskiana (Magnoliaceae), a new species of section Macrophylla from the central Sierra Madre Oriental, Mexico. Acta Botanica Mexicana, 112, 19-36.

Vázquez-García, J. A., Gómez-Domínguez, H., López-Cruz, A., Espinosa-Jiménez, J. A., Sahagún-Godínez, E., \& Muñiz-Castro, M. Á. (2013). Magnolia perezfarrerae, a new species and a key to mexican species of Magnolia (section Talauma, subsection Talauma, Magnoliaceae). Botanical Sciences, 91(4), 417-425.

Vázquez-García, J. A., Muñiz-Castro, M. Á., Arroyo, F., Pérez, Á. J., Serna, M., Cuevas Guzmán, R., ... Gurrola-Díaz, C. M. (2013). Novelties in neotropical Magnolia and an addendum proposal to the IUCN Red List of Magnoliaceae. In J. A. Vázquez-garcía, M. Á. Múñiz-Castro, E. Salcedo Pérez, E. Hernández Álvarez, T. Escoto García, \& N. Díaz Echavarría (Eds.), Recursos Forestales en el Occidente de México: Diversidad, Manejo, Producción, Aprovechamiento y Conservación. Guadalajara: Universidad de Guadalajara.

Vázquez-García, J. A., Muñiz-Castro, M. Á., De Castro-Arce, E., Murguía Araiza, R., Nuño Rubio, A. T., \& Cházaro-Basañez, M. de J. (2012). Twenty new neotropical tree species of Magnolia (Magnoliaceae). In E. Salcedo Pérez, E. Hernández Álvarez, J. A. Vázquez-García, T. Escoto García, \& N. Díaz Echavarría (Eds.), Recursos Forestales en el Occidente de México: Diversidad, Manejo, Producción, Aprovechamiento y Conservación (1a ed., pp. 91-130). Guadalajara: Universidad de Guadalajara.

Vázquez-García, J. A., Neill, D. A., Pérez-Castro, Á. J., Arroyo, F., Núñez, M. P., Serna, M., ... González, A. S. (2014). Magnoliaceae en el Neotrópico: Riqueza, endemismo y estado de conservación. XI Congreso Latinoamericano de Botánica, (October), 10. https://doi.org/10.13140/2.1.4945.6324

Vázquez-García, J. A., Pérez-Farrera, M. Á., Martínez-Camilo, R., Muñiz-Castro, M. Á., \& Martínez-Meléndez, N. (2013). Magnolia lacandonica (subsection Talauma, Magnoliaceae), a new rainforest species from Chiapas, Mexico. Phytotaxa, 79(1), 3036. https://doi.org/10.11646/phytotaxa.79.1.2

Vázquez-García, J. A., Pérez-Farrera, M. Á., Martínez-Meléndez, N., Nieves-Hernández, G., \& Muñiz-Castro, M. Á. (2012). Magnolia mayae (Magnoliaceae), a new species from 
Recibido:

23/marzo/2019

Aceptado: 25/noviembre/2019
Chiapas, Mexico. Botanical Sciences, 90(2), 109-112.

Vovides, A. P., Linares, E., \& Bye, R. (2010). Jardines botánicos de México: historia y perspectivas (1a ed.). Jalapa, Veracruz: Institudo de Ecología.

Waizel-Bucay, J. (2002). Uso tradicional e investigacion cientifica de Talauma mexicana (D.C.) Don., o flor del corazon. Revista Mexicana de Cardiologia, 13(1), 31-38.

Wang, L., Xiao, A. H., Ma, L. Y., Chen, F. J., Sang, Z. Y., \& Duan, J. (2017). Identification of Magnolia wufengensis (Magnoliaceae) cultivars using phenotypic traits, SSR and SRAP markers: Insights into breeding and conservation. Genetics and Molecular Research, 16(1). https://doi.org/10.4238/gmr16019473

Weising, K., Nybom, H., Wolff, K., \& Kahl, G. (2005). DNA Fingerprinting in Plants: Principles, Methods, and Applications.

White Olascoaga, L., Juan Pérez, J. I., Cedillo Gutiérrez, J. G., \& Chávez Mejía, C. (2013). Flora Medicinal En San Nicolás, Municipio De Malinalco, Estado de México. Polibotánica, 2(3), 173-206. https://doi.org/10.1007/s11104-008-9796-9

Ximénez, F. (1615). Cuatro libros de la naturaleza y virtudes de las plantas y animales de uso medicinal en la Nueva España. Retrieved from http://bdh-rd.bne.es/viewer.vm?pid=d211882 